\title{
Reciprocal interferences between nucleosomal organization and transcriptional activity of the yeast SNR6 gene
}

\author{
Marie-Claude Marsolier, ${ }^{1,4,6}$ Shigeo Tanaka, ${ }^{2,6}$ Magda Livingstone-Zatchej, ${ }^{2,6}$ Michael Grunstein, $^{3}$ \\ Fritz Thoma, ${ }^{2,6}$ and André Sentenac ${ }^{1,5,6}$ \\ ${ }^{1}$ Service de Biochimie et de Génétique Moléculaire, CEA-Saclay, F91191, Gif-sur-Yvette CÉDEX, France; \\ ${ }^{2}$ Institut für Zellbiologie, Eidgenössische Technische Hochschule, ETH-Hönggerberg, CH-8093 Zurich, Switzerland, \\ ${ }^{3}$ Department of Biological Chemistry, School of Medicine and the Molecular Biology Institute, University of California, Los \\ Angeles, California 90095 USA
}

Recent work has demonstrated a repressive effect of chromatin on the transcription of the yeast SNR6 gene in vitro. Here, we show the relations between chromatin structure and transcriptional activity of this gene in vivo. Analysis of the SNR6 locus by micrococcal nuclease digestion showed a protection of the TATA box, nuclease-sensitive sites around the $A$ and $B$ blocks, and arrays of positioned nucleosomes in the flanking regions. Analysis of a transcriptionally silent SNR6 mutant containing a 2-bp deletion in the B block showed a loss of TATA-protection and rearrangement or destabilization of nucleosomes in the flanking regions. Hence, SNR6 organizes the chromatin structure in the whole region in a manner dependent on its transcriptional state. Transcriptional analysis was performed by use of maxi-gene SNR6 constructs introduced into histone-mutated strains. Chromatin disruption induced by histone $\mathrm{H} 4$ depletion stimulated the transcription of promoter-deficient, but not of wild-type SNR6 genes, revealing a competition between the formation of nucleosomes and the assembly of Pol III transcription complexes that was much in favor of transcription factors. On the other hand, amino-terminal mutations in histone $\mathrm{H} 3$ or $\mathrm{H} 4 \mathrm{had}$ no effect (H4) or only a moderate stimulatory effect $(\mathrm{H} 3)$ on the transcription of promoter-deficient $S N R 6$ genes.

[Key Words: Saccharomyces cerevisiae; SNR6; chromatin; transcription; histone]

Received August 29, 1994; revised version accepted January 10, 1995.

A large number of studies carried out both in vitro and in vivo have established a globally repressive effect of chromatin on transcription, even if in some cases /Thomas and Elgin 1988; Cullen et al. 1993; Lu et al. 1993; Schild et al. 1993) a positive role of chromatin has been suggested through positioned nucleosomes bringing regulatory sequences closer to each other. In vivo, inhibition of transcription via positioned nucleosomes has been suggested for several genes, but the mechanisms are not known. In yeast, activation of the PHO5 promoter is accompanied by disruption of four positioned nucleosomes, including the nucleosome that covers the TATA box (Almer et al. 1986). Similarly, it was proposed that repression of a-cell-specific genes by the $22-\mathrm{MCM} 1$ complex acts by positioning of a nucleosome over the

${ }^{4}$ Present address: Laboratoire du Métabolisme, INRA-Versailles, Route de St-Cyr, F78026 Versailles, France.

${ }^{5}$ Corresponding author.

${ }^{6}$ Workers from these two laboratories contributed equally to this work.
TATA box (Roth et al. 1990, 1992; Ganter et al. 1993). However, it was reported recently that transcription remains repressed irrespective of whether the TATA box is located on a nucleosome or in an internucleosomal linker region (Patterton and Simpson 1994). A more global repression effect of chromatin (which could not be due to precisely positioned nucleosomes) on RNA polymerase II (Pol II) transcription in vivo in yeast has been demonstrated by Grunstein and co-workers, who showed that partial loss of nucleosomes activated reporter genes linked to basal promoters derived from genes as different as PHO5, CYC1, GAL1 (Han and Grunstein 1988), CUP1, and HIS3 (Durrin et al. 1992).

Numerous studies have also focused on chromatinmediated repression of RNA polymerase III (Pol III) genes in vivo. The $5 \mathrm{~S}$ rRNA genes have been subjected to intense investigation, especially the Xenopus oocyte-type $5 \mathrm{~S}$ genes whose transcription was found to be repressed by chromatin in somatic cells, with histone $\mathrm{H} 1$ playing a 
key role in this process (Schlissel and Brown 1984; Wolffe 1989|. In vitro studies with Xenopus egg extracts, which mimic in vivo conditions in terms of transcription, DNA replication, and chromatin assembly, have demonstrated a competition between the formation of transcription complexes and of nucleosomes on replicating $5 \mathrm{~S}$ templates, resulting in the establishment of selective repression of $5 \mathrm{~S}$ gene transcription (Almouzni et al. 1990). Yeast 5 S genes do not seem to be under the same constraints, because in vivo nucleosome disruption was not found to stimulate their transcription (Kim et al. 1988). Yeast tRNA genes also appear to be very resistant to chromatin-mediated repression. Even if a yeast tRNA gene could be repressed by insertion into the silent $H M R$ mating-type locus (Schnell and Rine 1986), the SUP4 tRNA $^{\text {Tyr }}$ gene was found able to override two different nucleosome positioning signals in vivo (Morse et al. 1992), and, as for the 5 S genes, no overall transcriptional stimulation of tRNA genes was triggered by nucleosome loss in yeast (Kim et al. 1988).

Burnol et al. (1993a) demonstrated recently that the yeast U6 RNA gene, SNR6, was repressed in vitro after chromatin assembly in Xenopus egg extracts or after nucleosome reconstitution with purified histones. This yeast Pol III gene presents some unusual features in its promoter elements: Its A block, at position +21 , is degenerate when compared with the consensus tRNA gene element; its B block is located downstream of the termination signal, 202 bp away from the A block; and it has a TATA box at position -30 (Brow and Guthrie 1990). Naked DNA templates of SNR6 gene can be transcribed effectively in vitro with purified transcription factor (TF) TFIIIB and Pol III, and the presence of the extragenic B block is not required for this process (Moenne et al. 1990; Margottin et al. 1991; Joazeiro et al. 1994). In contrast, the B block was found to be an essential promoter element in vivo (Brow and Guthrie 1990). This paradox was resolved by the demonstration that the chromatin repression observed in vitro was relieved by the interaction of TFIIIC with the B block, establishing a new, antirepressor function for this transcription factor (Burnol et al. 1993a).

In this paper we present an investigation of the relation between chromatin structure and transcriptional activity of wild-type and mutant SNR6 genes in vivo. The nucleosomal organization of the SNR6 locus was determined at nucleotide resolution and was shown to undergo dramatic changes upon the inactivation of the SNR6 gene by a 2-bp deletion in its B block. The competition between the establishment of chromatin structure and the binding of transcription factors was demonstrated by an increase in the transcript levels of SNR6 mutant genes following in vivo disruption of nucleosomes. In these experiments, the transcriptional activity of the wild-type SNR6 gene remained unchanged, indicating that class III transcription factors can compete successfully with histones. Finally, we show that mutations in the amino-terminal domain of histone $\mathrm{H} 3$, but not histone $\mathrm{H} 4$, can enhance the transcription of mutant SNR6 genes.

\section{Results \\ Chromatin structure of the SNR6 locus}

The SNR6 locus, shown schematically in Figure 1A, comprises the transcribed sequence of the SNR6 gene and its promoter elements, the TATA box, and the A and B blocks. In the $5^{\prime}$ region of the SNR6 gene, spanning base pairs -425 to -91 relative to SNR6 transcription start site, lies a solo $\delta$ element with its TATA box and upstream activating sequences (UASs). $\delta$ elements are the long terminal repeats (LTRs) of Tyl or Ty2 retrotransposons and are responsible for initiation of Ty transcription by Pol II (the 5' LTR) and for polyadenylation of the transcript (the 3' LTR). However, short RNA transcripts representing initiation and termination within the same LTR (or solo $\delta$ element) are not found in yeast cells (for review, see Boeke and Sandmeyer 1992).

To investigate whether the inactivation of the SNR6 gene by a 2-bp deletion in its B block would affect chromatin structure, chromatin of the wild-type SNR6 locus and of the mutated locus were analyzed with respect to nucleosome organization by use of micrococcal nuclease (MNase) digestions. MNase preferentially attacks linker DNA between nucleosomes and leads to double-strand cuts (Noll 1974), but it may also introduce single-strand nicks on the nucleosome surface (Cockell et al. 1983). To define nucleosome positions unambiguously, doubleand single-strand cutting information is required. Genomic chromatin and deproteinized DNA were digested with different amounts of MNase. Double-strand cutting sites were displayed by indirect end-labeling (low resolution mapping; Fig. 1B, C). Primer extension was used to display the cutting sites on the bottom and top strands at high resolution (Fig. 2). An interpretation of the results is summarized in Figure 3.

The chromatin studies of the wild-type SNR6 locus were done in yeast strains of different origins: GCY5 was derived from YM262 (Johnston and Davis 1984) and was used previously for chromatin studies (Cavalli and Thoma 1993). FTY113 and FTY114 were derived from YPH500 $\alpha$ (Sikorski and Hieter 1989). The chromatin structures of the wild-type locus were indistinguishable in these different strains (Fig. 1B,C; Fig. 2). With MNase mapping (Figs. 1 and 2), the bands in the $D$ lanes represent the preferential cutting sites for MNase in deproteinized DNA. Some of these sites were protected by chromatin (indicated on the left side of Fig. 1B), whereas others were accessible (indicated on the right side of Fig. $1 \mathrm{~B}$ and Fig. 2, A-D). A protected region of $140-200 \mathrm{bp}$ was interpreted as a positioned nucleosome (open box) (Thoma et al. 1984).

At low resolution, the chromatin structure of the wildtype SNR6 upstream region shows a series of nucleosomes positioned on the solo $\delta$ sequences (nucleosomes $-1,-2,-3$ ) and on the flanking genomic DNA (nucleosome -4) (Fig. 1B,C). At high resolution, nucleosomes -1 to -4 can be clearly identified as protections in the top strand (bars in the CHR lanes of Fig. 2A,B) and on the bottom strand (bars in Fig. 2C,D). The major cutting sites recorded at high resolution agree very well with the sites 
Figure 1. A 2-bp deletion in the B block disrupts chromatin structure in the SNR6 gene and in the flanking regions. (A) A schematic view of the SNR6 locus (according to Brow and Guthrie 1988, 1990|. The SNR6 and solo $\delta$ regions, the TATA boxes $\langle T\rangle$, the solo $\delta$ UAS and potential initiation site (I), the $A$ and $B$ blocks $(A, B)$, the transcribed region of $S N R 6$ (arrow), the relevant restriction sites (SspI, HpaI, PstI), and the DNA fragment used to generate a probe (bar) are indicated. Distances (in base pairs) are from the SNR6 transcription start site (1). (B) Chromatin structure of the wild-type SNR6 locus (strain GCY5). Chromatin (lanes C) and deproteinized DNA (lanes D) were digested with various concentrations of MNase. The cutting sites were mapped by indirect end-labeling from the $\mathrm{HpaI}$ site (position 630). The numbers represent averaged measurements of two gels with a total of nine chromatin lanes and four deproteinized DNA lanes. The standard deviations were below \pm 10 bp for cutting sites between 466 and -334 , and below $\pm 10-20$ bp for sites between -367 and -711 . Protected and accessible sites are labeled on the left and right, respectively. An interpretive diagram is shown at right. SNR6 and solo $\delta$ promoter elements are denoted by the same abbreviations as in $A$, except for the solo $\delta$ UAS, which is designated by U. Protected regions of $140-200$ bp are interpreted as positioned nucleosomes fopen boxes, $-1,-2,-3,-4,1)$. Partial protec-

tion of sites at 85 and 206 may suggest a nucleosome on the wild-type SNR6 gene (hatched box; for details see text). The protection over the SNR6 TATA box is marked $(O)$. $(C)$ Chromatin structure of the wild-type (strain FTY113, wt) and mutant SNR6 locus with a 2-bp deletion in the B block (strain FTY115, $\Delta 2$ ). The cutting sites in chromatin (lanes C) and deproteinized DNA (lanes D) were mapped by indirect end-labeling from the PstI site located about position 830 . The major accessible sites and interpretive diagrams of the wild-type and mutated loci are shown at right and left, respectively. The naked DNA pattern of FTY115 was indistinguishable from that of FTY113 (not shown). Nucleosome positioning is lost in the $\Delta 2$ mutant, which is denoted by the absence of open boxes, and the SNR6 TATA region becomes hypersensitive to MNase (arrowhead). Moreover, the solo $\delta$ TATA box becomes protected (stippled circle), and a putative nucleosome could be present in the $3^{\prime}$ end of the mutated SNR6 locus (stippled box). Note that the chromatin structure inferred by this method always reflects the average structure of a population.

mapped at low resolution (Fig. 3). With respect to the putative functional elements of the solo $\delta$, the UAS was found in the linker region between nucleosomes -1 and -2 . In contrast, the TATA box of solo $\delta$ was localized in nucleosome -2 . On the basis of the double-strand cuts (Fig. 1), this nucleosome was placed on a position be- tween -214 and -367 . At high resolution, the cutting sites in the bottom and top strands did not overlap precisely, in particular each strand showed additional cutting on the $5^{\prime}$ end of the putative nucleosome -2 . Major cuts in the top strand were at -220 and -368 , with additional cuts around -345 (Figs. $2 \mathrm{~B}$ and 3 ). The bot-

Figure 2. Chromatin structure at high resolution of wild-type and mutant SNR6 loci. Strains FTY113 and FTY114 harbor a wild-type chromosomal SNR6 locus (wt) whereas FTY115 has a 2-bp mutation in the SNR6 B block that inactivates the gene ( $\triangle 2)$. The cutting sites of MNase in chromatin (CHR) and deproteinized DNA (D) were displayed by linear primer extension for the top strand $(A, B)$ and the bottom strand $(C, D)$ (lanes 5-19). Increasing levels of digestion are shown $(<)$. Lanes 1-4 represent the genomic sequence of the mutated SNR6 locus (C, T, A, and G refer to the sequence on the template strand). The promoter elements of the solo $\delta$ region and of the SNR6 gene are marked by vertical bars at lane $G$. The major sites accessible in wild-type chromatin and interpretive diagrams of the wild-type SNR6 locus are shown right. Abbreviations (T, A, B, U) and symbols are as in Fig. 1; positioned nucleosomes are indicated by open boxes. The SNR6 TATA box is accessible in the mutant (arrowhead on the diagram and in the CHR lanes) and protected in the wild-type gene (open ellipse). Major protected regions are also indicated by bars at the CHR lanes. A dot at position 236 (Fig. 2A) illustrates an altered sequence specificity for MNase resulting from the $\Delta 2$ deletion. 
tom strand, however, displayed a major cut that we interpret to be the end of the nucleosome at -368 (Fig.
$2 \mathrm{Cl}$, whereas the $5^{\prime}$ end showed a series of cuts between -220 and -255 . Hence, the TATA box, which is located

A
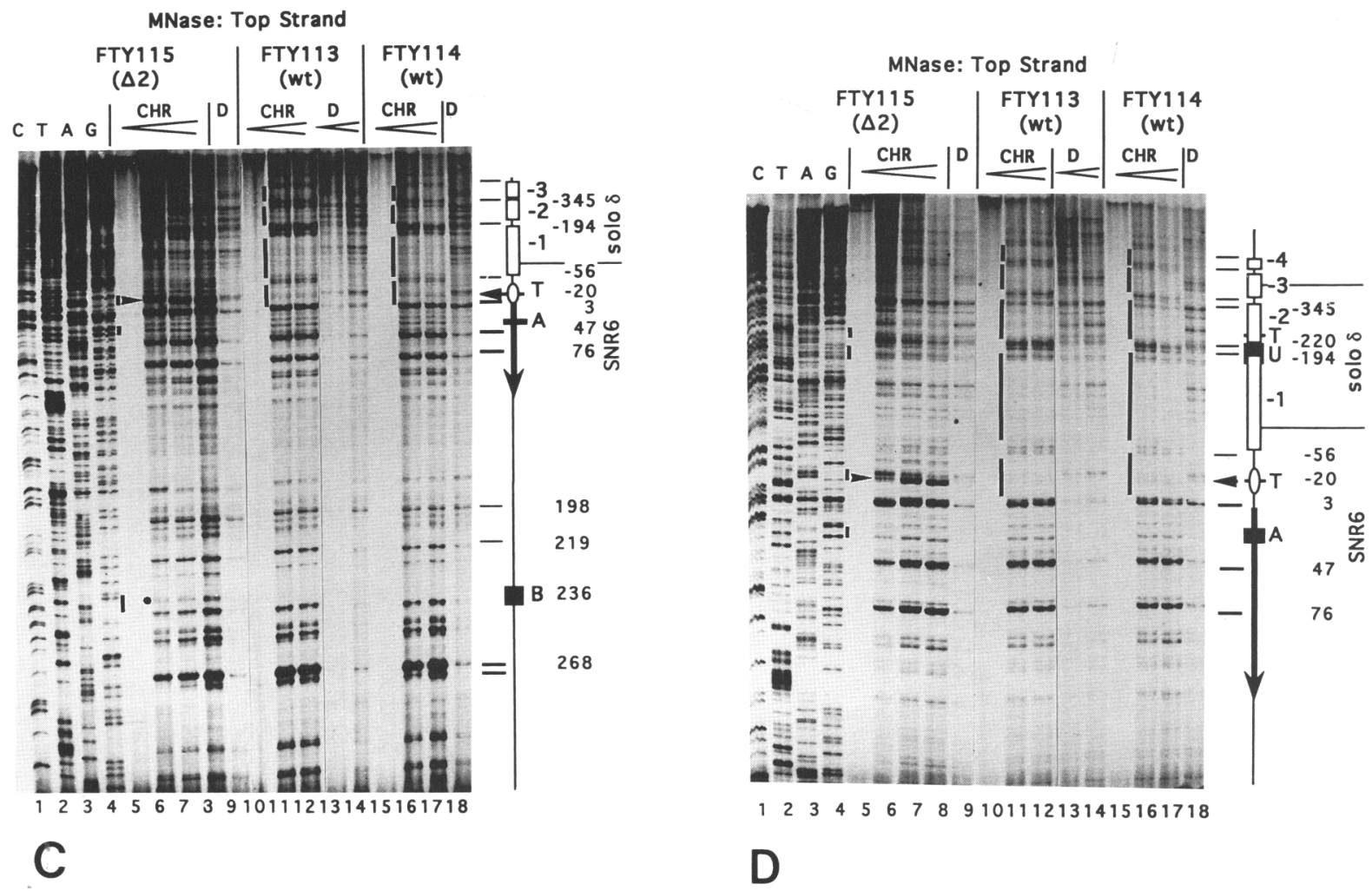

MNase: Bottom Strand
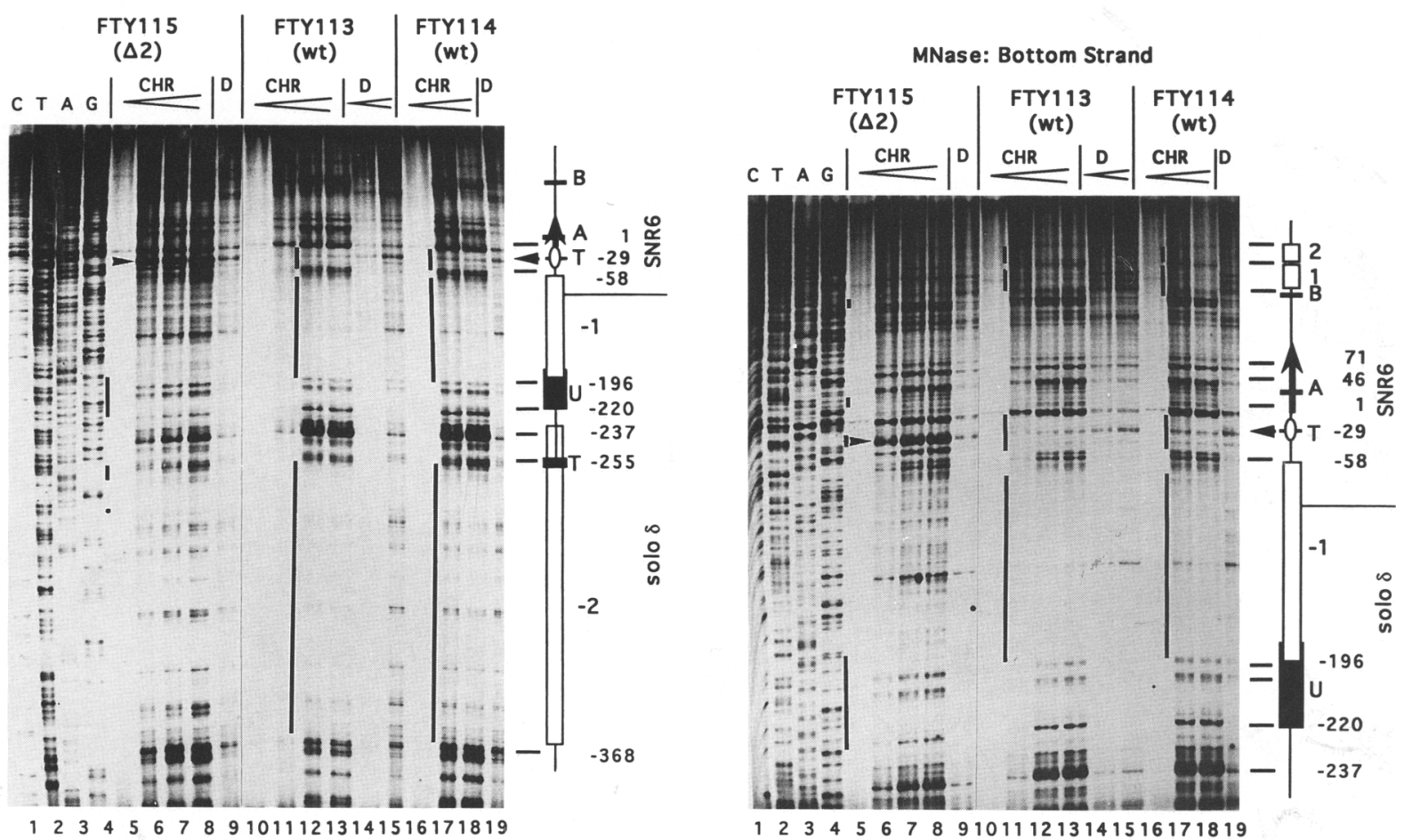

Figure 2. (See facing page for legend.) 

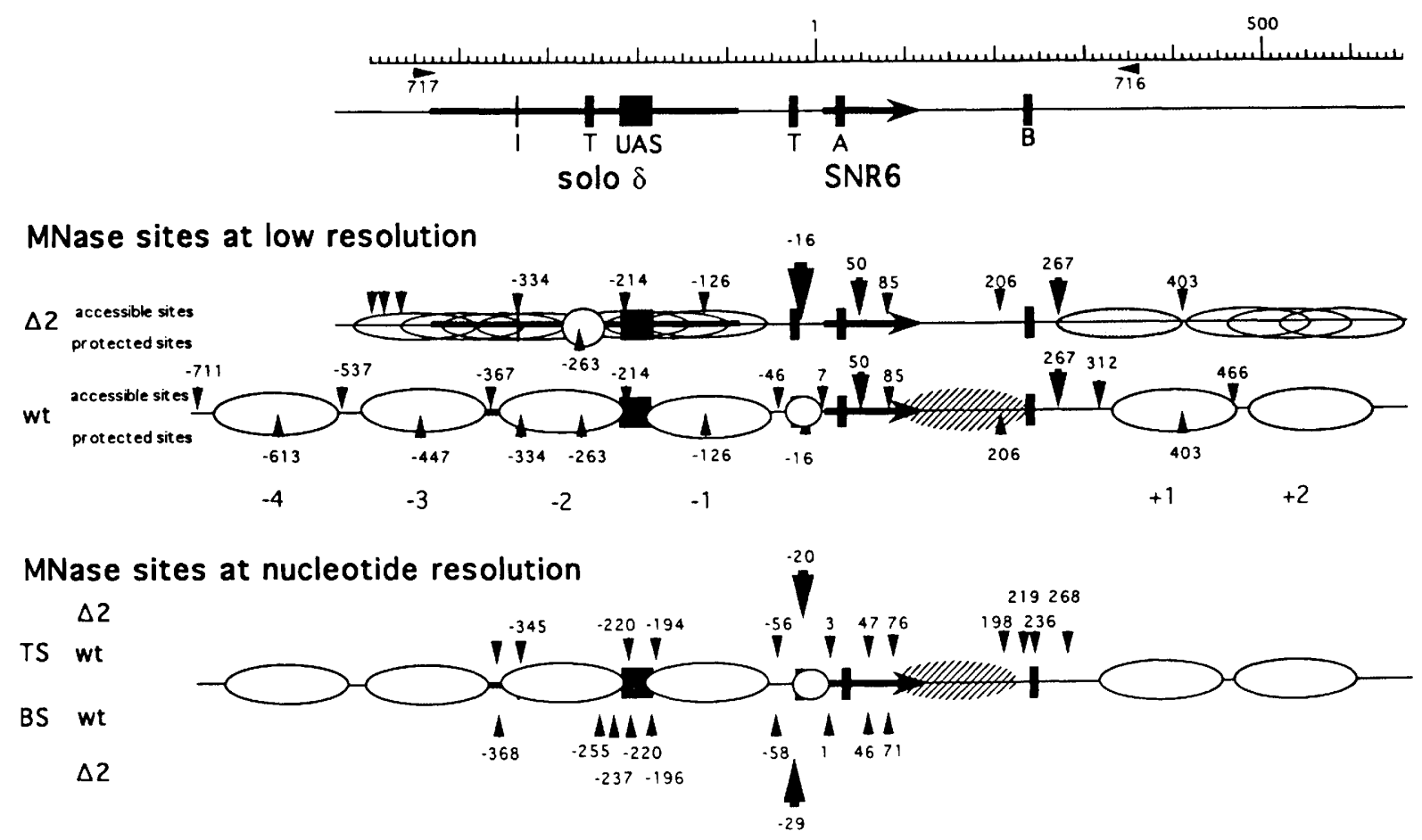

Figure 3. Chromatin changes at the SNR6 locus. The diagrams summarize the positions of the MNase sites at low and nucleotide resolutions, and provide a global interpretation of the nucleosomal structure of both the wild-type (wt) and mutant ( $\Delta 2$ ) SNR6 loci. The major diagnostic cutting sites for MNase are illustrated: Arrows mark double-strand cuts at low resolution and top and bottom strands (TS and BS) cuts at nucleotide resolution. Positioned nucleosomes are indicated by open ellipses. Transparent ellipses indicate weak protection, compatible with the presence of a nucleosome but not strongly supporting it, overlapping ellipses suggest a loss of nucleosome positioning or a loss of nucleosomes. A hatched ellipse in the SNR6 gene indicates that a nucleosome might lead to the partial protection observed at 85 and 206. Protection of the TATA boxes in the SNR6 gene and the solo $\delta$ element are marked by circles.

around -255 , was protected in the top strand but accessible on the bottom strand.

The SNR6 gene is characterized by a protection of the TATA box and hypersensitive sites around the A block and close to the B block. Three chromatin-specific cutting sites were found around the TATA box and the A block (Fig. 1, hypersensitive sites $-46,7,50$ ). This observation was substantiated by a series of cuts at these positions on the top and bottom strands (Fig. 2). Most dramatically, the TATA box, which showed up as a band in naked DNA (Fig. 1, lanes D, site - 16), was protected by chromatin. This was also evident at high resolution on the top and bottom strands (arrowheads in Fig. 2). In contrast to the TATA box, no protection of the A block was obvious. Two chromatin-specific hypersensitive sites were also observed $3^{\prime}$ of the B block (Fig. 1B,C, hypersensitive sites 267,312 ). The B block DNA itself was not a preferred substrate for MNase (no doublestrand cuts in lanes D) nor was it cut in chromatin. The region between the $A$ and the $B$ blocks was difficult to interpret. No strong cutting sites for MNase are available between 85 and 206 on deproteinized DNA that would allow an unambiguous estimate of their protection by chromatin.
Downstream of the B block, a site at 403 was protected and a site at 466 was accessible (Fig. 1B,C). This suggests that a nucleosome is positioned between 312 and 466 . Analysis of the bottom strand revealed at least two positioned nucleosomes downstream of SNR6 (Fig. 2D, nucleosomes 1,2$)$.

The structure of the SNR6 locus is summarized in Figure 3. SNR6 characteristics include protection of the TATA box, hypersensitive sites close to the A and B blocks, and a series of positioned nucleosomes in the $3^{\prime}$ and $5^{\prime}$-flanking regions.

\section{A 2-bp deletion in the $B$ block disrupts protection over the TATA box of the SNR6 gene}

FTY115 is a yeast strain in which the SNR6 gene was inactivated by a 2-bp deletion in the B block. The strain was rescued by a wild-type gene placed on a plasmid. Chromatin analysis by MNase revealed a dramatic loss of protection in the TATA region of the silent chromosomal gene. Although a double-strand site at -16 was protected in the wild-type SNR6 gene (Fig. 1B,C, GCY5 and FTY113), it was heavily cut in the $\Delta 2$ mutant FTY115 (arrowhead, Fig. 1C). The enhanced accessibility 
was confirmed at high resolution on the top and bottom strands (arrowheads in Fig. 2B,D; cf. chromatin lanes of the wild-type gene and the $\Delta 2$ mutant).

Because relief of repression by TFIIIC was required for in vitro transcription only when the DNA was packaged in chromatin (Burnol et al. 1993a), we expected that a lack of TFIIIC binding to the mutated B block would allow nucleosome formation on the SNR6 gene. However, neither a protection of the TATA box, the A block, nor the B block region by a nucleosome was observed on the silent gene (Figs. 1 and 2). No substantial differences were recorded at low and high resolution in the chromatin structure of the wild-type and mutant SNR6 genes, except for the TATA region.

In conclusion, the major effect of the mutation in SNR6 B block was the loss of protection in the TATA box, suggesting that TFIIIC is required to recruit and stabilize the TATA-binding initiation complex in genomic chromatin.

\section{A 2-bp deletion in the B block disrupts chromatin structure in the $5^{\prime}$ - and $3^{\prime}$-flanking regions of SNR6}

To our surprise, the effects of the B block mutation on chromatin structure were not confined to the TATA region of the SNR6 gene but extended on both sides into the flanking sequences. Downstream of the SNR6 gene, the protection that characterized nucleosomes 1 and 2 was lost in the mutant (Fig. 2D), indicating that nucleosomes, if still present, might have been rearranged. Furthermore, site 312 was partially protected in the mutant and site 403 became more accessible (Fig. 1C). This suggests that at least a fraction of nucleosomes might be positioned between 267 and 403 (stippled box, Fig. 1C). Hence, in this case, the downstream nucleosome 1 would have changed its position.

Upstream of the SNR6 gene, the chromatin structure of the solo $\delta$ region was severely affected by the mutation in the B block. Instead of the clear nucleosomal pattern observed in the wild-type locus, more cleavage sites were accessible in the mutant, but their positions were still different from the cutting pattern in deproteinized DNA (Figs. 1C and 2B,C). This indicated that nucleosomes were disrupted or rearranged (the presence of nucleosomes in this region could not be directly tested by hybridization of a nucleosomal repeat with solo $\delta$ sequences, because solo $\delta$ sequences are highly repetitive in the genome). The TATA box of the solo $\delta$ element is located in a protected region (Fig. 1C, lanes 1-3, between -214 and -334$)$. This region is unlikely to be covered by a positioned nucleosome, because it is only $\sim 120 \mathrm{bp}$ long and shorter than the nucleosome footprint observed in the wild-type locus (Fig. 1C, lane 4, between -214 and -367$)$. In contrast to the protection over the TATA box of the wild-type SNR6 gene, the protection over the solo $\delta$ TATA box in the mutant SNR6 locus was revealed only by mapping the double-strand sites, whereas the top and the bottom strands mapped separately showed substantial cutting. Hence, whatever the component that created that protection, it was associated with the DNA in a way that allowed the individual strands to be cut separately.

Chromatin structure of the wild-type SNR6 gene and of the $\Delta 2$ mutant in centromeric plasmids

Gene structure and function are frequently and efficiently tested on plasmid constructs. Because gene expression can be affected by the local chromatin structure and because chromatin structure can be altered by new flanking regions, we tested whether and to what extent chromatin structures were maintained when the $1-140$; +314 ) region of the wild-type and mutant SNR6 genes was placed on plasmids. The chromatin structure of the wild-type SNR6 gene and the $\Delta 2$ B block mutant, harbored on the centromeric plasmid pRS314, were tested by MNase digestion and indirect end-labeling (Fig. 4).

In the vector regions ( $p R S 314$ ), the cutting pattern of MNase was very similar in deproteinized DNA (lanes D) and in chromatin (lanes C). No protection was obvious that might indicate the positioning of nucleosomes, which suggests that nucleosomes were arranged randomly on bacterial sequences. With respect to the wildtype SNR6 gene, cutting at the TATA box (site - 16) was clearly protected and the chromatin-specific sites at -46 and 7 were accessible (e.g., Fig. 4B, lane 6). On the other hand, cutting at the hypersensitive sites at 50,85 , and 267 was less pronounced in plasmid chromatin and site 206 was more accessible (Figs. 1B and 4B, cf. sites 267 and 206 in plasmid and genomic DNA). When the B block deletion mutant was analyzed, the TATA box was accessible to MNase (Fig. 4, lanes 3,4,9) demonstrating a similar loss of protection as was observed in the genomic mutation. Furthermore, the chromatin pattern was similar to the deproteinized DNA pattern, indicating that nucleosomes, if present, were not positioned.

In conclusion, the chromatin structure was less clear on the plasmids than in the genome, but it showed the characteristic features and the mutation-dependent transitions. It must be pointed out that no effect of the SNR6 gene on the flanking plasmid regions was observed, in contrast to the genomic chromatin organization.

\section{Nucleosome disruption leads to an increase} in the transcript level of mutant

but not wild-type SNR6 genes

To investigate the effect of chromatin on SNR6 transcription in vivo, and the part that the different promoter elements of SNR6 could play in relieving it, we used the in vivo nucleosome disruption system developed by Grunstein and co-workers (Han and Grunstein 1988; Han et al. 1988; Kim et al. 1988). They constructed a strain, UKY403, whose two genes encoding histone H4 (H4-1 and H4-2) have been disrupted, and which survives with a unique histone $\mathrm{H} 4$ gene placed under control of the GAL1 promoter on a centromeric plasmid (Kim et al. 1988|. H4 mRNA synthesis is thus activated by galactose and repressed by glucose. After a shift to a glucose-containing medium, the UKY403 cells undergo about one round of cell division before arresting in $G_{2}$, at which 


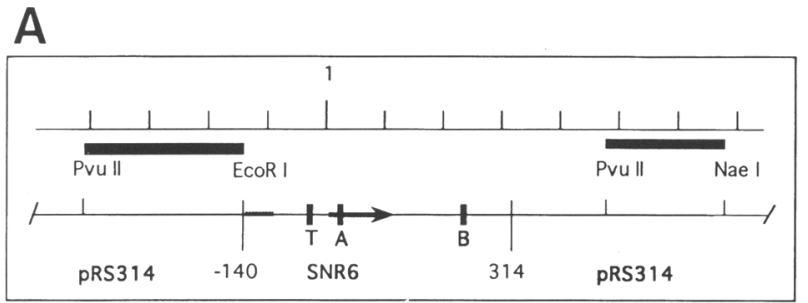

B

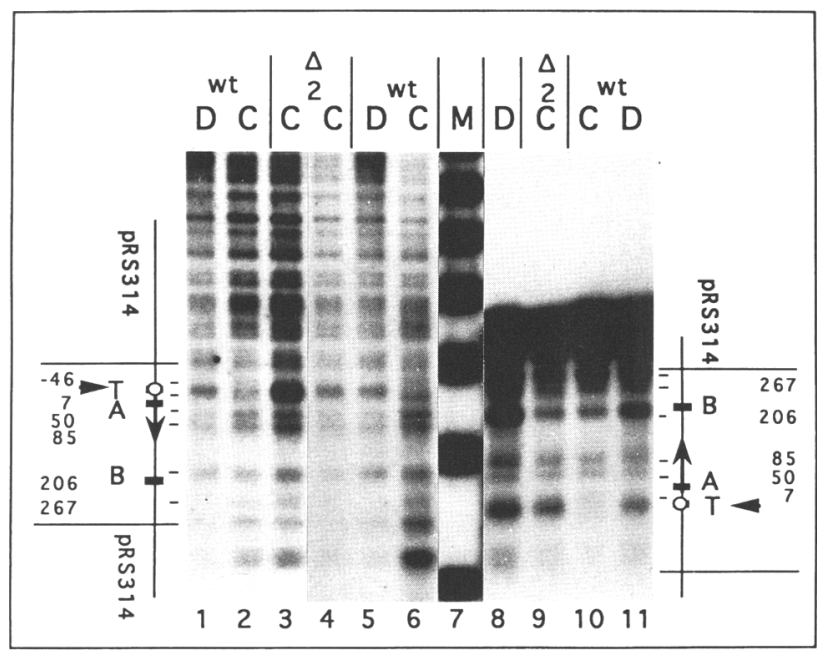

Figure 4. Chromatin structure of wild-type and $\Delta 2$ mutant SNR6 genes in centromeric plasmids. (A) The wild-type SNR6 gene (wt) and the mutant $\Delta 2$ gene $(\Delta 2)$ were placed on pRS314 plasmids and introduced into the YPH500 $\alpha$ strain. The relevant part of the constructs is illustrated: the SNR6 TATA box (T), A block (A), B block (B), and transcribed region (arrow) are indicated, as well as the fragments used as probes (bars). (B) Chromatin (lanes C) and deproteinized DNA (lanes D) were digested with various concentrations of MNase. The DNAs in lanes 1-2, $5-6,8$, and $10-11$ are from the pRS314 plasmid harboring the wild-type (wt) SNR6 gene, and the DNAs in lanes 3-4 and 9 from the plasmid harboring the $S N R 6 \Delta 2$ mutant $(\Delta 2)$. A DNA ladder consisting of multiples of $256 \mathrm{bp}$ was used for calibration (M, lane 7). The cutting sites were mapped from the NaeI site with a NaeI-PvuII probe (lanes $1-6$ ) and from the PvuII site with a PvuII-EcoRI probe (lanes 8-11). Relevant cutting sites for MNase and diagrams are shown at sides. The TATA box was protected in the wild-type $S N R 6$ gene $(O)$ and accessible in the $\Delta 2$ mutant (arrowhead). Almost no difference was observed between lanes $C$ and $D$ in the pRS314 regions, indicating that nucleosomes were randomized.

stage the density of nucleosomes on the DNA is approximately half the normal level (Kim et al. 1988). These events are referred to as nucleosome disruption or nucleosome loss. To analyze the relationship between chromatin structure and SNR6 transcription, various SNR6 genes harboring wild-type or mutated promoter elements were introduced into UKY403 cells.

We analyzed several mutant SNR6 genes, which are described in Figure 5B. The mutations called TATAdown, Adown and $B \Delta 2$ /which was also used for the chromatin structure analysis| destroy, respectively, the TATA box, the A block, and the B block. Two constructs were truncated at position +122 and lacked the B block, Bdel and (Bdel + Aup). The mutation Binv has the B block inverted, whereas the Aup mutation replaces the degenerate A block by a consensus A block derived from the sequences of tRNA A blocks (Burnol et al. 1993b). The $(-140 ;+314)$ SNR6 construct, used previously to analyze nucleosomal structure (Fig. 4), was mutated as described above and inserted into the multicopy YEp352 plasmid. An unrelated 59-bp DNA fragment was introduced into the transcribed region of the gene, at position +73 , so as to distinguish the corresponding transcripts from the endogenous, wild-type U6 RNA.

UKY403 cells containing the various $S N R 6$ constructs were grown on galactose and then transferred to a glucose-containing medium for $6 \mathrm{hr}$. Figure 5A shows the steady-state transcript levels of both endogenous and episomal SNR6 genes monitored by Northern blots, before and after the glucose shift. It can be noted that the SNR6 maxi-genes, harbored on multicopy plasmids, had relatively much lower levels of transcripts than the wildtype, chromosomal gene, probably because of the 59-bp insertion in their transcribed sequences, which could alter either their rates of transcription or the half-life of their transcripts. In vivo, the $A$ and $B$ blocks are essential promoter elements of the SNR6 gene, whereas the TATA box is dispensable and contributes with the A block to the selection of the transcription start site (Brow and Guthrie 1990; Burnol et al. 1993b, Chalker and Sandmeyer 1993; Eschenlauer et al. 1993). Accordingly, with a normal chromatin structure (before glucose shift), the transcripts produced from the constructs $\mathrm{B} \Delta 2$, Bdel, or Adown were hardly detectable on Northern blots (Fig. $5 \mathrm{~A}$, lane 9), even after a long exposure (lanes $11,13,15$ ). The Binv and (Bdel + Aup) constructs, which are affected in their TFIIIC-binding sequences, were also transcribed less efficiently $\{15$ and $7 \%$ of the wild-type level, respectively, lanes 5,7$)$. The TATAdown construct (lane 3) generated about half as many $(40 \%)$ transcripts as the wild-type construct (WT, lane 1); and, in that case, the transcripts were slightly shorter, in agreement with previous observations on the role of the TATA box in the selection of the transcriptional start site.

After nucleosome disruption, the chromosomal gene and the plasmid-borne wild-type construct showed no difference in transcriptional activity. In contrast, all of the gene constructs with mutated promoter elements presented a marked increase in transcript levels upon repression of histone $\mathrm{H} 4$ synthesis. For the TATAdown construct, nucleosome loss restored an accumulation of transcripts equivalent to the wild type (Fig. 5A, lane 4), and the transcript levels of the Binv and the (Bdel + Aup) constructs were increased strongly to $80 \%$ and $52 \%$ the level of the wild-type construct, respectively (lanes 6,8). The amount of transcripts generated from the B blockless genes, B $\Delta 2$, and Bdel, was also increased after glucose shift, even though the transcriptional activity of these genes remained very low (lanes 12,14). Finally, the presence of transcripts derived from the Adown construct became detectable following nucleosome disruption (lane 16). The size of the transcripts was the same 

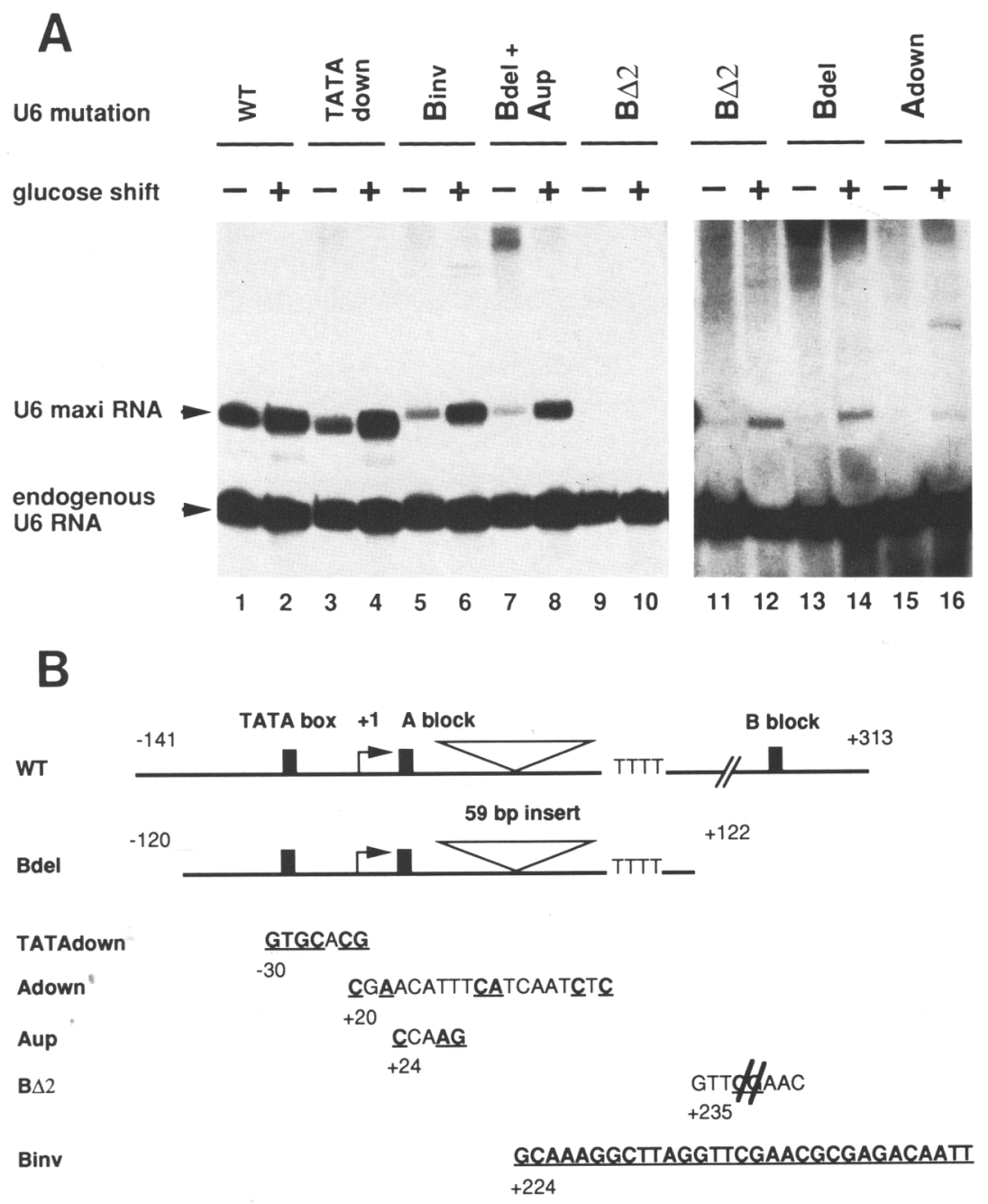

Figure 5. Activation of mutant SNR6 genes by depletion of histone $\mathrm{H} 4$ and nucleosomes. (A) The Northern blot illustrates the transcriptional activation of SNR6 genes harboring a 59-bp insert in the transcribed region and different mutations. These genes are on multicopy plasmids and generate transcripts (U6 maxi-RNA) easily distinguishable from the endogenous U6 RNA produced from the wild-type, chromosomal SNR6 gene. Plasmids harboring the SNR6 mutant genes were introduced into the yeast strain UKY403, which contains a unique histone $\mathrm{H} 4$ gene under the control of the GAL1 promoter. Cells were grown in galactose-based medium until they reached an $\mathrm{OD}_{660}$ of 0.3 (indicated as glucose shift - land then transferred to a glucose medium for $6 \mathrm{hr}$ (glucose shift + ). (Right; lanes 11-16) The autoradiography of the gel was about four times longer. $(B)$ Mutants analyzed. All plasmids contain the entire SNR6 RNA gene, from position -140 to +314 , except for the Bdel and the (Bdel + Aup) plasmids, which harbor a truncated fragment (from -120 to +122 ), without the B block. The mutations affecting the SNR6 promoter elements (the TATA box and the A and B blocks) are described (the scheme is not drawn to scale). The nucleotides that have been mutated are underlined, and all positions refer to the transcriptional start site $(+1)$. before and after the glucose shift, suggesting that the activation of the SNR6 genes by nucleosome disruption did not alter the transcription start site.

To check that these effects were related to nucleosome depletion and not to the galactose to glucose metabolic change and the consecutive modification of the cell growth rate, similar experiments were performed with the control strain MHY308. MHY308 is a strain isogenic to UKY403 except that its sole histone $\mathrm{H} 4$ gene is under control of its own wild-type promoter (Han and Grunstein 1988). After a similar shift from galactose to glucose, no significant increase in the transcript level of any SNR6 construct could be observed in this strain (data not shown).

We conclude that the transcriptional activation of promoter-deficient $S N R 6$ genes was attributable to depletion of histone $\mathrm{H} 4$. The wild-type SNR6 genes, on the other hand, were apparently insensitive to the chromatin state.

Mutations in the amino-terminal domain of histone $H 3$, but not $H 4$, enhance the transcriptional activity of mutated SNR6 genes

Grunstein and co-workers have demonstrated that deletions or mutations of the amino-terminal domains of histones $\mathrm{H} 3$ and $\mathrm{H} 4$ had specific effects on the transcriptional activation of Pol II genes (Durrin et al. 1991; Johnson et al. 1992; Mann and Grunstein 1992; Roth et al. 1992). Because we had some evidence of chromatinmediated effects on the transcription of the SNR6 gene, we investigated whether these mutations could also affect in vivo the transcription of wild-type or mutant SNR6 genes.

Grunstein and co-workers (Durrin et al. 1991; Mann and Grunstein 1992) have constructed two series of yeast strains lacking either histone $\mathrm{H} 3$ or $\mathrm{H} 4$ genes that survive with centromeric plasmids harboring wild-type or mutated versions of either the histone $\mathrm{H} 3-2$ or $\mathrm{H} 4-2$ genes under control of their own promoter. The wildtype, TATAdown, Binv, and B $\Delta 2$ constructs were introduced into yeast strains variously mutated on histone $\mathrm{H} 3$ or $\mathrm{H} 4$ genes, and the corresponding transcripts were monitored by Northern blots.

Three yeast strains mutated in the histone $\mathrm{H} 4-2$ gene were tested: PKY817 and PKY813, which contain aminoterminal deletions of this gene (residues 4-14 and 4-28, respectively), and LDY107, in which the first four lysine residues of histone $\mathrm{H} 4-2$ were substituted by glutamine (Durrin et al. 1991). None of these mutations was found 
to induce significant changes in the transcript levels of wild-type or mutant SNR6 genes (Fig. 6A; data not shown).

Four yeast strains mutated in the histone H3-2 gene were analyzed. No significant change in the transcriptional activity of the SNR6 genes could be observed in yeast strains RMY410 and RMY430, which contain amino-terminal deletions of the $\mathrm{H} 3-2$ gene (residues 4-10 and 4-30, respectively; Fig. 6B; data not shown). In contrast, we found that two mutations affecting the acetylation sites of histone $\mathrm{H} 3-2$ could enhance the transcriptional levels of SNR6 genes mutated in their B blocks. The histone $\mathrm{H} 3$ mutations, which either replaced the first three acetylation sites (lysine residues) by three glycine or changed the first four acetylation sites to arginine, allowed some increase in the transcriptional activity of the SNR6 constructs affected in the B block, B inv, and $B \Delta 2$ (Fig. 6B, lanes $G$ and $R$, respectively).

\section{Discussion}

The wild-type SNR6 gene functions as an organizer of local chromatin structure

In the wild-type situation, the transcriptionally active U6 RNA gene is flanked on both its $5^{\prime}$ and $3^{\prime}$ regions by arrays of positioned nucleosomes. This structure is lost on the transcriptional inactivation of the gene by a 2-bp deletion in the distant B block, which prevents TFIIIC binding. This result represents the first evidence that a transcriptionally active Pol III gene can exert a boundary effect and organize the chromatin structure of its flanking regions. The effect is original in that it is linked to the integrity of SNR6 B block. The yeast $\alpha 2$ repressor is a protein that positions nucleosomes by factor-mediated contacts with histones (Roth et al. 1990; Shimizu et al. 1991; Ganter et al. 1993; Cooper et al. 1994). By analogy to the $\alpha 2$ repressor, it is proposed that TFIIIC might organize the nucleosomal structure of SNR6 $5^{\prime}$ region by recruiting the components that induce a strong protection around the TATA box (likely TFIIIB, see below) and that could spread nucleosome positioning in the upstream region. Similarly, (transient) binding of TFIIIC to the B block could establish nucleosome positioning on the 3 ' side. Alternatively, we cannot exclude that the transcription process itself could affect nucleosome positioning in SNR6-flanking regions. Whatever the mechanisms involved in this process, and the specific interactions between the components of the Pol III machinery and the adjacent nucleosomes, the SNR6 boundary effect was not observed when the gene was inserted in the centromeric vector pRS314: The bacterial sequences of the plasmid were not organized into sets of positioned nucleosomes, which suggests the presence of either sequence-specific effects or episomal constraints different from the chromosomal ones and incompatible with SNR6-induced chromatin organization.

In yeast, tRNA genes that are transcribed by Pol III are frequently found near the upstream control regions of genes transcribed by Pol II or downstream of Ty retrotransposons or free solo $\delta$ regions. It was shown recently that a tRNA gene may inhibit transcription from adjacent Pol II promoters (Hull et al. 1994). This inhibition required active transcription of the tRNA gene but was independent of its orientation. It was considered that repression might occur by competitive interactions of transcription factors, by steric interference, or by chro-
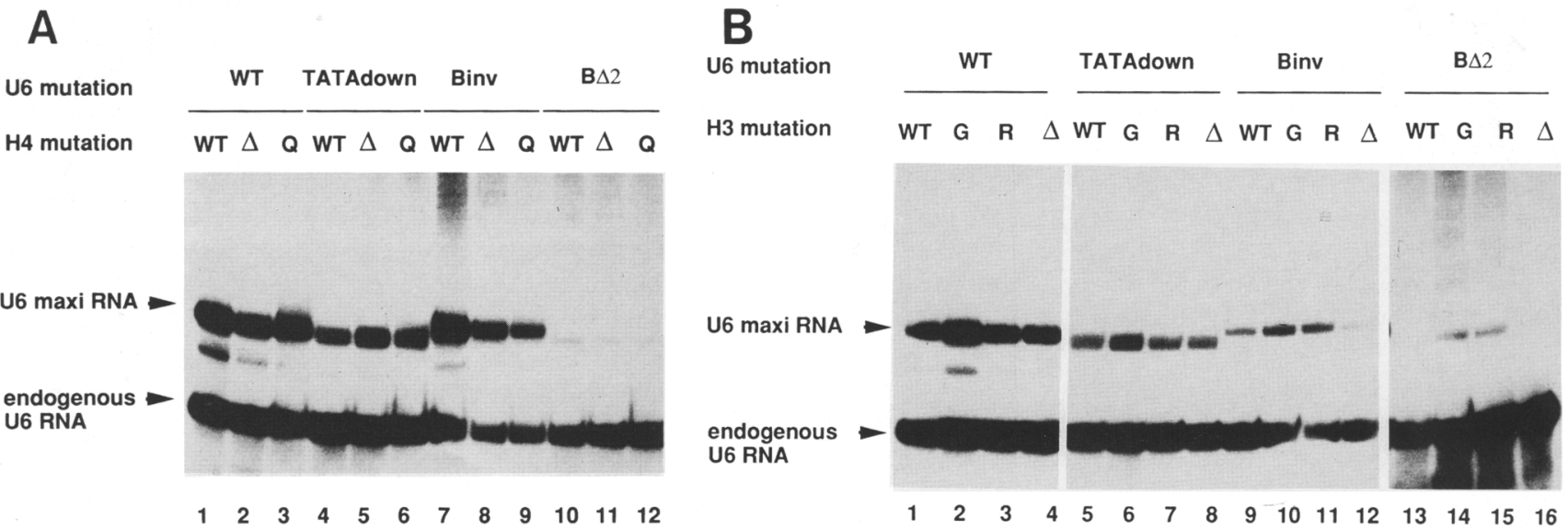

Figure 6. SNR6 mutant RNA levels in yeast strains with wild-type or amino-terminally mutated histones $\mathrm{H} 4-2(A)$ or $\mathrm{H} 3-2(B)$. Mutant SNR6 genes, harbored on multicopy plasmids, were introduced into wild-type and variant yeast strains, and the accumulation of the corresponding transcripts (U6 maxi-RNA) was monitored by Northern blot. The mutant SNR6 genes (TATAdown, Binv, B $\Delta 2$ ) are described in Fig. 5B. The variant yeast strains mutated in the histone H4-2 or H3-2 genes are indicated as follows: (A) Wild-type (WT) yeast strain PKY501 with wild-type histone H4-2; (A), yeast strain PKY813 with histone H4-2 deleted from residue 4 to 28; (Q) yeast strain LDY107 with the first four acetylation sites (positions 5, 8, 12, and 16) substituted for by glutamine (Durrin et al. 1991). (B) Wild-type (WT) yeast strain RMY200 with wild-type histone H3-2; G) yeast strain RMY247 with the first three acetylation sites of H3-2 (positions 9, 14, and 18) changed in glycine; (R) yeast strain RMY253 with the first four acetylation sites of histone H3-2 (positions 9, 14, 18, and 23) substituted for by arginine; ( $\Delta$ ) yeast strain RMY430 with histone H3-2 deleted from residue 4 to 30 (Mann and Grunstein 1992). (B $\Delta 2)$ The autoradiography was three times longer. 
matin structure (Hull et al. 1994). The SNR6 locus represents a similar situation with a solo $\delta$ element immediately upstream of SNR6. In this case, it is shown clearly that the wild-type, active SNR6 gene organizes the nucleosome arrangement in the solo $\delta$ region. Although the UAS of solo $\delta$ overlapped the ends of nucleosomes -1 and -2 , the TATA box of solo $\delta$ was located within nucleosome -2 (Fig. 3). In the $\Delta 2$ mutant, nucleosome positioning was lost but the solo $\delta$ TATA box was occupied by something different from a nucleosome. These results support chromatin repression as a mechanism by which tRNA genes could affect flanking Pol II promoters. It must be noted that the effect on chromatin structure was observed on both sides of SNR6, which is consistent with the observation that the repression was independent of the orientation of the tRNA genes (Hull et al. 1994). RNA transcripts representing initiation and termination within a solo $\delta$ element are normally not found in yeast cells. However, it would be interesting to test whether transcription from the solo $\delta$ element is indirectly stimulated by the $\Delta 2$ mutation in the SNR6 gene.

\section{Analysis of protein/DNA contacts provides insights into the mechanism of SNR6 transcription}

In vitro, on naked SNR6 DNA, the binding of TFIIIC to the $B$ block leads via DNA looping to a weak, secondary interaction between TFIIIC and the A block region, observed by electron microscopy (Burnol et al. 1993b). Once bound, TFIIIC stimulates the formation of TFIIIBSNR6 complexes but the TATA box provides sufficient information for proper, TFIIIC-independent binding of TFIIIB (Joazeiro et al. 1994).

Remarkably, MNase digestions of chromatin revealed a protection of the TATA box, but not of the A and B blocks, on the wild-type SNR6 gene. This result was confirmed by DNase I digestions (not shown). The protection of the TATA box and of the $5^{\prime}$ region was strictly linked to the transcriptional activity of the SNR6 gene. Furthermore, the extent of this protection (from about -46 to 7 , MNase, Fig. 3 ; -41 to -3 , DNase I, not shown) was comparable to TFIIIB footprinting on naked SNR6 DNA in vitro (from -40 to -10 ; Joazeiro et al. 1994), which strongly suggests that it is attributable to the binding of TFIIIB. The increased nuclease sensitivity of the TATA box in the mutant SNR6 gene might then reflect a loss of TFIIIB or at least altered binding properties of the factor. In contrast, no substantial differences were recorded in the region of the A or B blocks between the wild-type and mutant SNR6 loci, and we found no evidence for the continuous presence of TFIIIC on the active U6 RNA gene. This suggests that TFIIIC does not stay permanently bound to the U6 RNA gene. These results can be compared with in vivo footprinting experiments performed with tRNA or 5S rRNA genes. Except for the potentially active somatic 5S RNA genes of the transcriptionally quiescent Xenopus erythrocytes, where a strong protection of the internal control region (ICR), presumably by TFIIIA, was observed (Chipev and Wolffe 19921, no evidence was found for the permanent binding of the assembly factors TFIIIA or TFIIIC on active $5 \mathrm{~S}$ RNA or tRNA genes (Huibregtse and Engelke 1989; Engelke and Gottesfeld 1990). In contrast, the proximal upstream region of the same genes was clearly protected, indicating the presence of TFIIIB (Huibregtse and Engelke 1989; Chipev and Wolffe 1992). These observations support the hypothesis that TFIIIA and TFIIIC might be only temporarily bound to their promoter sequences, so as to recruit TFIIB, and might dissociate hereafter leaving TFIIIB alone to direct the initiation of transcription by Pol III, as suggested by in vitro experiments (Kassavetis et al. 1990).

Another aspect of SNR6 transcription that we wanted to investigate was the potential presence of a nucleosome between the A and the B blocks. The unusual location of SNR6 B block 202 bp away from the A block [whereas the optimal length of A-B spacing in terms of transcriptional efficiency for tRNA and VA RNA genes was found to be 30-60 bp (Cannon et al. 1986; Baker et al. 1987; Fabrizio et al. 1987/] had led several investigators (Burnol et al. 1993b; Eschenlauer et al. 1993) to propose the existence of a DNA loop stabilized or structurally organized by a nucleosome positioned between the $A$ and B blocks (static loop model). Our data do not allow us to unambiguously conclude about the presence of a nucleosome between the A and B blocks, which cannot be completly ruled out. However, chromatin does not appear to have a positive role in U6 RNA transcription because nucleosome loss via histone $\mathrm{H} 4$ depletion did not reduce the transcriptional activity of the wild-type SNR6 gene (Fig. 5A).

\section{Chromatin-mediated repression of SNR6 transcription}

Consistent with the demonstration by Burnol et al. (1993a) of a repressive effect of nucleosome assembly on the transcription of the SNR6 gene in vitro, we found that nucleosome disruption induced an increase in the transcript levels of plasmid-born U6 RNA genes mutated either at the TATA box or at the A or B blocks. However, the wild-type gene, with intact promoter elements, remained apparently insensitive to chromatin changes. Although we cannot rule out indirect effects of nucleosome loss on transcription of mutant U6 RNA genes, the consistency of these results with the in vitro data leads us to assume that they reflect a competition between nucleosomal organization and the binding of transcription factors on the SNR6 gene. This competition is largely in favor of the transcription factors and becomes apparent only when the efficiency of the transcription machinery is weakened through mutations of promoter elements. It is not clear how the repressive effect of the nucleosomes evidenced by these experiments works. The analysis of the chromatin structure of the mutated SNR6 gene, either on the pRS314 plasmid or in the genome, demonstrated that the inactivation of the gene did not lead to the incorporation of its promoter or transcribed sequences into positioned nucleosomes. The repressive effect of chromatin on SNR6 transcription thus could occur through variably or randomly placed nucleosomes. This also seems to be the case for the Xenopus oocyte- 
specific 5S rRNA in kidney-derived cell lines (Engelke and Gottesfeld 1990), whereas in erythrocyte nuclei the majority of the oocyte 5S DNA repeats appears to be assembled into weakly positioned nucleosomal arrays (Chipev and Wolffe 1992).

The effect of nucleosome depletion on the transcriptional efficiency of the various $S N R 6$ constructs allows us to evaluate the main steps of the transcriptional complex assembly that are competed for by nucleosome formation in this plasmidic context. For both the Binv and the (Bdel + Aup) constructs, the only parameter that can be improved following nucleosome disruption is the binding of TFIIIC to the A block. Indeed (Bdel+ Aup) lacks the B block and the B block of Binv is merely inverted without alteration of sequence; besides, both constructs have wild-type 5 ' sequences. Accordingly, the increase in Binv and (Bdel + Aup) transcript level upon nucleosome loss reflects the competition between TFIIIC and the nucleosomes at the level of the A block. Similarly, the increase of TATAdown transcripts reflects the competition between nucleosomes and TFIIIC-dependent binding of TFIIIB at the $5^{\prime}$ end of the gene.

The A and B block-less genes (B $\Delta 2$, Bdel, and Adown) stand apart in that, whatever the chromatin structure, they probably cannot be bound productively by TFIIIC on the A block so as to recruit TFIIIB. Therefore, we believe that the low amount of transcripts generated by the $\mathrm{B} \Delta 2$, Bdel, and Adown constructs upon nucleosome loss is due to TFIIIC-independent binding of TFIIIB, similar to the TFIIIC-independent positioning of TFIIIB on naked DNA in vitro (Burnol et al. 1993b, Joazeiro et al. 1994). These mutant SNR6 genes can be compared with Grunstein and co-workers' constructs containing the basal promoters of CYC1 and GAL1 fused to the $1 a c Z$ reporter gene (Durrin et al. 1992). Both these Pol II constructs and the mutant A or B block-less SNR6 genes are devoid of enhancer or enhancer-like sequences and have their levels of transcription strongly increased by nucleosome disruption. However, in both cases, the transcription levels induced by chromatin disruption remain 25 to 50-fold lower than the levels of transcription induced by the corresponding full promoters. Accordingly, TFIIIB recruitment via protein-protein interactions, rather than chromatin anti-repression, would seem to be the predominant function of TFIIIC regarding the SNR6 gene in vivo. In vitro data, however, suggested that TFIIIC could function essentially as an antirepressor with an accessory role of enhancing the recruitment of TFIIIB (Moenne et al 1990; Burnol et al. 1993a; Joazeiro et al. 1994). These observations can be conciliated if one considers that the nucleosome loss induced by histone $\mathrm{H} 4$ depletion leads only to a partial, probably nonhomogeneous, disruption of chromatin, which remains a template very different from the naked DNA used for the in vitro experiments.

Having established the antirepressor function of TFIIIC for the SNR6 gene in vivo, we searched for mutations in the histone $\mathrm{H} 3$ or $\mathrm{H} 4$ genes that could affect, positively or negatively, the interactions between the Pol III transcription machinery and the nucleosomes.
Durrin et al. (1991) demonstrated that mutations in the amino-terminal domain of yeast histone $\mathrm{H} 4$ reduced considerably the activation of several but not all Pol II genes (GAL1,-7,-10 but not GAL4 or PRC1). However, none of the mutations tested affected the transcript levels of wild-type or mutant SNR6 genes. In contrast, we found that two mutations modifying the acetylation sites of histone $\mathrm{H} 3$ significantly enhanced the transcriptional activity of SNR6 genes mutated in their B blocks. The same mutations also allowed hyperactivation of the GAL1 gene (but not of the PHO5 or PRC1 genes, Mann and Grunstein 1992). It is not clear why these mutations have that effect on the SNR6 gene, which was not exhibited by the deletion of the residues $4-30$. These results can be interpreted in two ways: Either the two mutations slightly modify the structure of the nucleosomes, allowing them to be more easily, passively displaced from the SNR6 initiation site, or these mutations somehow specifically enhance the interactions between the chromatin and the Pol III transcription machinery, leading to a more efficient displacement of the nucleosomes from the transcriptional start site. The precise interactions between histones and transcription complexes remain to be determined.

\section{Material and methods}

Plasmids

All plasmids contain the region of the SNR6 gene spanning base pairs -140 to +314 relative to SNR6 transcription start site, except for the Bdel and (Bdel + Aup) constructs, which harbor a truncated fragment from -120 to +122 , lacking the B block (Burnol et al. 1993b). These fragments were mutated as described (Fig. 5B; Burnol et al. 1993b). To study the transcriptional activity of wild-type, and mutant SNR6 genes in yeast strains mutated on their histone $\mathrm{H} 3$ or $\mathrm{H} 4$ genes, a 59-bp XbaIHincll DNA fragment from the Bluescript SK vector (BSSK, Stratagenel was inserted into the transcribed region, at the EcoNI site (position +73 ). This insertion maps at the beginning of the third loop of the predicted RNA secondary structure (Fortner et al. 1994). Once generated in BSSK plasmids, the constructs were transferred to multicopy vectors, YEp352 (Hill et al. 1986 ) and pRS424 (Christianson et al. 1992).

For chromatin studies of wild-type and mutant SNR6 genes on plasmids, a DNA fragment encompassing the SNR6 gene $(-140 ;+314)$ with either a wild-type or a mutated B block $(\Delta 2)$ was introduced into the centromeric plasmid pRS314 (Sikorski and Hieter 1989 | to give pRS314-U6 and pRS314- $\Delta 2$ respectively.

To create the 2-bp deletion in the B block of the SNR6 chromosomal locus, the SNR6 DNA fragment $(-140$; +314) containing the $\mathrm{B} \Delta 2$ mutation (Fig. $5 \mathrm{~B}$ ) was cloned into the integrative vector pRS306 (Sikorski and Hieter 1989) to give pRS306$\Delta 2$. All mutations were controlled by DNA sequencing.

\section{Strains}

The Saccharomyces cerevisiae strains used for these studies were derived from YM262 (GCY5) or YPH500 $\alpha$ (FTY113, FTY114, FTY115). FTY 113 and FTY114 are transformants of YPH500 $\alpha$, containing the pRS314-U6 and pRS314- $\Delta 2$ plasmids respectively. FTY115 corresponds to the strain YPH500 $\alpha$ with the $\mathrm{B} \Delta 2$ mutation at its SNR6 chromosomal locus, which is rescued by the centromeric plasmid pRS314-U6. This strain was 
constructed as follows: YPH500 $\alpha$ was first transformed with the integrative plasmid pRS306- $\Delta 2$, and a clone with pRS306- $\Delta 2$ integrated at the SNR6 locus was selected following EcoRIHpaI analysis of genomic DNA / the $\mathrm{B} \Delta 2$ mutation creates a HpaI sitel. This clone was transformed with the pRS314-U6 plasmid, and recombination events at the SNR6 locus were then selected by plating of the cells on 5-fluoro-orotic acid (5-FOA) plates. The genomic DNA of the 5-FOA-resistant clones was analyzed by EcoRI-HpaI digest, and FTY 115 was a clone that had conserved the mutated gene at the SNR6 locus. This restriction analysis was finally confirmed by direct genomic sequencing (Fig. 2A).

UKY403, MHY308, PKY501, PKY813, PKY817, LDY107, RMY200, RMY247, RMY253, RMY410, and RMY430 have been described by Kim et al. (1988), Han and Grunstein (1988), Durrin et al. (1991), and Mann and Grunstein (1992).

\section{Chromatin analysis by MNase}

Preparation of genomic chromatin, digestion with MNase and mapping of nucleosome positions were done as described (Thoma et al. 1984; Bernardi et al. 1991). The DNA was cut to completion with a restriction endonuclease, fractionated on $1 \%$ agarose gels, blotted to nitrocellulose, and hybridized to radioactively labeled probes as indicated in the legend to Figure 1. Radioactive probes were made by random priming using a labeling kit (Pharmacia). A DNA ladder consisting of multiples of $256 \mathrm{bp}$ was used for calibration (Thoma et al. 1984).

Mapping chromatin structure at nucleotide resolution MNase cleavage sites were analyzed by primer extension with Taq DNA polymerase (Shimizu et al. 1991; Roth et al. 1992). The digested DNA was purified on ELUTIP-d columns /Schleicher \& Schuell, D-3354 Dassel, Germany). The primer used for mapping the top strand was primer $7165^{\prime}$-CGTACCATTGCATAGCTGTAACAATATTC-3' (from base pairs 363 to 335). The primer used for bottom strand mapping was primer $7175^{\prime}$ AATTTATATTGCTACCATGACTGTCTGAG-3' (from base pairs -449 to -421 ). The primers were labeled at the $5^{\prime}$ end with polynucleotide kinase and $\left[\gamma^{32} \mathrm{P}\right]$ ATP (Maniatis et al. 1982). Ten microliters $(\sim 1 \mu \mathrm{g})$ of the DNA was mixed with $9 \mu \mathrm{l}$ of 0.3 pmole $5^{\prime}$ end-labeled primer $\left(5 \times 10^{5}\right.$ to $\left.1 \times 10^{6} \mathrm{cpm}\right), 5 \mu \mathrm{l}$ of $5 \times$ Taq buffer $150 \mathrm{~mm}$ Tris- $\mathrm{HCl} \mathrm{pH} 8.3,250 \mathrm{mM} \mathrm{KCl}, 15 \mathrm{~mm}$ $\mathrm{MgCl}_{2}$ ). After the samples were heated at $95^{\circ} \mathrm{C}$ for $5 \mathrm{~min}$ and chilled in ice water, $1.2 \mu \mathrm{l}$ of nucleotide mixture $15 \mathrm{~mm}$ each dGTP, dATP, dTTP, and dCTP) and 1 unit of Taq polymerase (Cetus, Perkin Elmer; in $5 \mu 11 \times$ Taq buffer) were added. The sample was overlayed by $\sim 25 \mu \mathrm{l}$ paraffin oil. Thirty cycles were run at $94^{\circ} \mathrm{C}$ for $1 \mathrm{~min}, 60^{\circ} \mathrm{C}$ for $2 \mathrm{~min}$, and $72^{\circ} \mathrm{C}$ for $3 \mathrm{~min}$. The water phase was transferred to a new tube, and the DNA was precipitated with one-tenth volume of $3 \mathrm{M}$ sodium acetate and three volumes of ethanol. DNA samples were electrophoresed at $1800 \mathrm{~V}$ for $2 \mathrm{hr}$ (short run) or $3.5 \mathrm{hr}$ (long run) on $4 \%$ polyacrylamide gels $(31 \mathrm{~cm} \times 38.5 \mathrm{~cm}$, width by height, BRL model S2) containing 50\% urea and $1 \times$ TBE (Maniatis et al. 1982). Sequencing of minichromosomes for comparison was done by the chain termination method with Taq polymerase.

\section{RNA analysis}

The multicopy plasmids YEp352 or pRS424, harboring the various SNR6 constructs, were introduced into yeast strains mutated on their histone $\mathrm{H} 3$ or $\mathrm{H} 4$ genes. Yeast transformation procedures, RNA extraction, and Northern blot analysis were performed as described (Burnol et al. 1993b), by use of a bodylabeled DNA fragment encompassing the U6 RNA-coding sequence $(-120$ to +122$)$. For the glucose shift experiments with the UKY403 and MHY308 strains, transformant cells contain- ing various plasmids with mutant SNR6 genes were first grown overnight in a selective, galactose-containing medium until they reached an $\mathrm{OD}_{660}$ of 0.3 . An aliquot was then taken and the remaining cells were shifted to a glucose-based medium and allowed to grow for another $6 \mathrm{hr}$ before being harvested.

\section{Acknowledgments}

We thank S. Shaaban for reviewing the manuscript. This research was supported by grants from the European Community (Science and Biotechnology programs) to A.S. and from the Swiss National Science Foundation to F.T.

The publication costs of this article were defrayed in part by payment of page charges. This article must therefore be hereby marked "advertisement" in accordance with 18 USC section 1734 solely to indicate this fact.

\section{References}

Almer, A., H. Rudolph, A. Hinnen, and W. Hörz. 1986. Removal of positioned nucleosomes from the yeast PHO5 promoter upon $\mathrm{PHO} 5$ induction releases additional upstream activating DNA elements. EMBO /. 5: 2689-2696.

Almouzni, G., M. Méchali, and A.P. Wolffe. 1990. Competition between transcription complex assembly and chromatin assembly on replicating DNA. EMBO /. 9: 573-582.

Baker, R.E., S. Camier, A. Sentenac, and B.D. Hall. 1987. Gene size differentially affects the binding of yeast transcription factor $\tau$ to two intragenic regions. Proc. Natl. Acad. Sci. 84: 8768-8772.

Bernardi, F., T. Koller, and F. Thoma. 1991. The ade6 gene of the fission yeast Schizosaccharomyces pombe has the same chromatin structure in the chromosome and in plasmids. Yeast 7: 547-558.

Boeke, J.D. and S.B. Sandmeyer. 1991. Yeast transposable elements. In The molecular and cellular biology of the yeast Saccharomyces (ed. J.R. Broach, J.R. Pringle, and E.W. Jones), 2nd ed., pp. 193-261. Cold Spring Harbor Laboratory Press, Cold Spring Harbor, New York.

Brow, D.A. and C. Guthrie. 1988. Spliceosomal RNA U6 is remarkably conserved from yeast to mammals. Nature 334: 213-218.

- 1990. Transcription of a yeast U6 snRNA gene requires a polymerase III promoter element in a novel position. Genes \& Dev. 4: 1345-1356.

Burnol, A.F., F. Margottin, J. Huet, G. Almouzni, M.N. Prioleau, M. Méchali, and A. Sentenac. 1993a. TFIIIC relieves repression of U6 snRNA transcription by chromatin. Nature 362: 475-477.

Burnol, A.F., F. Margottin, P. Schultz, M.C. Marsolier, P. Oudet, and A. Sentenac. 1993b. Basal promoter and enhancer elements of yeast U6 snRNA gene. I. Mol. Biol. 233: 644-658.

Cannon, R.E., G.J. Wu, and J.F. Railey. 1986. Functions of and interactions between the A and B blocks in adenovirus type 2-specific VARNAl gene. Proc. Natl. Acad. Sci. 83: 12851289.

Cavalli, G. and F. Thoma. 1993. Chromatin transitions during activation and repression of galactose-regulated genes in yeast. $E M B O$ J. 12: 4603-4613.

Chalker, D.L. and S.B. Sandmeyer. 1993. Sites of RNA polymerase III transcription initiation and Ty3 integration at the U6 gene are positioned by the TATA box. Proc. Natl. Acad. Sci. 90: $4927-4931$.

Chipev, C.C. and A.P. Wolffe. 1992. Chromosomal organization of Xenopus laevis oocyte and somatic 5S rRNA genes in vivo. Mol. Cell. Biol. 12: 45-55.

Christianson, T.W., R.S. Sikorski, M. Dante, J.H. Shero, and P. 
Hieter. 1992. Multifunctional yeast high-copy-number shuttle vectors. Gene 110: 119-122.

Cockell, M., D. Rhodes, and A. Klug. 1983. Location of the primary sites of micrococcal nuclease cleavage on the nucleosome core. J. Mol. Biol. 170: 423-446.

Cooper, J.P., S.Y. Roth, and R.T. Simpson. 1994. The global transcriptional regulators, SSN6 and TUP1, play distinct roles in the establishment of a repressive chromatin structure. Genes \& Dev. 8: 1400-1409.

Cullen, K.E., M.P. Kladde, and M.A. Seyfred. 1993. Interaction between transcription regulatory regions of prolactin chromatin. Science 261: 203-206.

Durrin, L.K., R.K. Mann, P.S. Kayne, and M. Grunstein. 1991. Yeast histone $\mathrm{H} 4 \mathrm{~N}$-terminal sequence is required for promoter activation in vivo. Cell 65: 1023-1031.

Durrin, L.K., R.K. Mann, and M. Grunstein. 1992. Nucleosome loss activates CUP1 and HIS3 promoters to fully induced levels in the yeast Saccharomyces cerevisiae. Mol. Cell. Biol. 12: $1621-1629$.

Engelke, D.R. and J.M. Gottesfeld. 1990. Chromosomal footprinting of transcriptionally active and inactive oocyte-type 5S RNA genes of Xenopus laevis. Nucleic Acids Res. 18: $6031-6037$.

Eschenlauer, J.B., M.W. Kaiser, V.L. Gerlach, and D.A. Brow. 1993. Architecture of a yeast U6 RNA gene promoter. Mol. Cell. Biol. 13: 3015-3026.

Fabrizio, P., A. Coppo, P. Fruscoloni, P. Benedetti, G. Di Segni, and G. Tocchini-Valentini. 1987. Comparative mutational analysis of wild-type and stretched tRNA3Leu gene promoters. Proc. Natl. Acad. Sci. 84: 8763-8767.

Fortner, D.M., R.G. Troy, and D.A. Brow. 1994. A stem/loop in U6 RNA defines a conformational switch required for premRNA splicing. Genes \& Dev. 8: 221-233.

Ganter, B., S. Tan, and T.J. Richmond. 1993. Genomic footprinting of the promoter regions of STE2 and STE3 genes in the yeast Saccharomyces cerevisiae. J. Mol. Biol. 234: 975-987.

Han, M. and M. Grunstein. 1988. Nucleosome loss activates yeast downstream promoters in vivo. Cell 55: 1137-1145.

Han, M., U.J. Kim, P. Kayne, and M. Grunstein. 1988. Depletion of histone $\mathrm{H} 4$ and nucleosomes activates the PHO5 gene in Saccharomyces cerevisiae. EMBO 1. 7: 2221-2228.

Hill, J.E., A.M. Myers, T.J. Koerner, and A. Tzagoloff. 1986. Yeast/E. coli shuttle vectors with multiple unique restriction sites. Yeast 2: 163-167.

Huibregtse, J.M. and D.R. Engelke. 1989. Genomic footprinting of a yeast tRNA gene reveals stable complexes over the $5^{\prime}$ flanking region. Mol. Cell. Biol. 9: 3244-3252.

Hull, M.W., J. Erickson, M. Johnston, and D.R. Engelke. 1994. tRNA genes as transcriptional repressor elements. Mol. Cell. Biol. 14: 1266-1277.

Joazeiro, C.A.P., G.A. Kassavetis, and E.P. Geiduschek. 1994. Identical components of yeast transcription factor IIIB are required and sufficient for transcription of TATA box-containing and TATA-less genes. Mol. Cell. Biol. 14: 27982808.

Johnson, L.M., G. Fisher-Adams, and M. Grunstein. 1992. Identification of a non-basic domain in the histine $\mathrm{H} 4 \mathrm{~N}$-terminus required for repression of the yeast silent mating loci. EMBO I. 11: 2201-2209.

Johnston, M. and R.W. Davis. 1984. Sequences that regulate the divergent GAL1-GAL10 promoter in Saccharomyces cerevisiae. Mol. Cell. Biol. 4: 1440-1448.

Kassavetis, G.A., B.R. Braun, L.H. Nguyen, and E.P. Geiduschek. 1990. S. cerevisiae TFIIIB is the transcrition initiation factor proper of RNA polymerase III, while TFIIIA and TFIIIC are assembly factors. Cell 60: 235-245.
Kim, U.J., M. Han, P. Kayne, and M. Grunstein. 1988. Effects of histone $\mathrm{H} 4$ depletion on the cell cycle and transcription of Saccharomyces cerevisiae. EMBO 1. 7: 2211-2219.

Lu, Q., L.L. Wallrath, H. Granok, and S.C.R. Elgin. 1993. (CT) n. GA/n repeats and heat shock elements have distinct roles in chromatin structure and transcriptional activation of the Drosophila hsp26 gene. Mol. Cell. Biol. 13: 28022814.

Maniatis, T., E. Fritsch, and J. Sambrook. 1982. Molecular cloning: A laboratory manual. Cold Spring Harbor Laboratory, Cold Spring Harbor, New York.

Mann, R.K. and M. Grunstein. 1992. Histone H3 N-terminal mutations allow hyperactivation of the yeast GALl gene in vivo. EMBO I. 11: 3297-3306.

Margottin, F., G. Dujardin, M. Gérard, J.M. Egly, J. Huet, and A. Sentenac. 1991. Participation of the TATA factor in transcription of the yeast U6 gene by RNA polymerase C. Science 251: 424-426.

Moenne, A., S. Camier, G. Anderson, F. Margottin, J. Beggs, and A. Sentenac. 1990. The U6 gene of Saccharomyces cerevisiae is transcribed by RNA polymerase C (III) in vivo and in vitro. EMBO 1. 9: 271-277.

Morse, R.H., S.Y. Roth, and R.T. Simpson. 1992. A transcriptionally active tRNA gene disrupts nucleosome positioning in vivo. Mol. Cell. Biol. 12: 4015-4025.

Noll, M. 1974. Subunit structure of chromatin. Science 251: 249-251.

Patterton, H.G. and R.T. Simpson. 1994. Nucleosomal location of the STE6 TATA box and Mata2p-mediated repression. Mol. Cell. Biol. 14: 4002-4010.

Roth, S.Y., A. Dean, and R.T. Simpson. 1990. Yeast $\alpha 2$ repressor positions nucleosomes in TRPl/ARSl chromatin. Mol. Cell. Biol. 10: 2247-2260.

Roth, S.Y., M. Shimizu, L. Johnson, M. Grunstein, and R.T. Simpson. 1992. Stable nucleosome positioning and complete repression by the yeast $\alpha 2$ repressor are disrupted by aminoterminal mutations in histone H4. Genes \& Dev. 6: 411425 .

Schild, C., F.X. Claret, W. Wahli, and A.P. Wolffe. 1993. A nucleosome-dependent static loop potentiates estrogen-regulated transcription from the Xenopus vitellogenin B1 promoter in vitro. EMBO I. 12: 423-433.

Schlissel, M.S. and D.D. Brown. 1984. The transcriptional regulation of Xenopus 5S RNA genes in chromatin: The roles of active stable transcription complexes and histone H1. Cell 37: 903-913.

Schnell, R. and J. Rine. 1986. A position effect on the expression of a tRNA gene mediated by the SIR genes in Saccharomyces cerevisiae. Mol. Cell. Biol. 6: 494-501.

Shimizu, M., S.Y. Roth, C. Szentgyorgyi, and R.T. Simpson. 1991. Nucleosomes are positioned with base pair precision adjacent to the alpha-2 operator in Saccharomyces cerevisiae. EMBO I. 10: 3033-3041

Sikorski, R.S. and P. Hieter. 1989. A system of shuttle vectors and yeast host strains designed for efficient manipulation of DNA in Saccharomyces cerevisiae. Genetics 122: 19-27.

Thoma, F., L.W. Bergman, and R.T. Simpson. 1984. Nuclease digestion of circular TRPIARSl chromatin reveals positioned nucleosomes separated by nuclease sensitive regions. I. Mol. Biol. 177: 715-733.

Thomas, G.H. and S.C.R. Elgin. 1988. Protein/DNA architecture of the DNase I hypersensitive region of the Drosophila hsp26 promoter. EMBO I. 7: 2191-2201.

Wolffe, A.P. 1989. Dominant and specific repression of Xenopus oocyte 5S RNA genes and satellite I DNA by histone $\mathrm{Hl}$. EMBO /. 8: 527-537. 


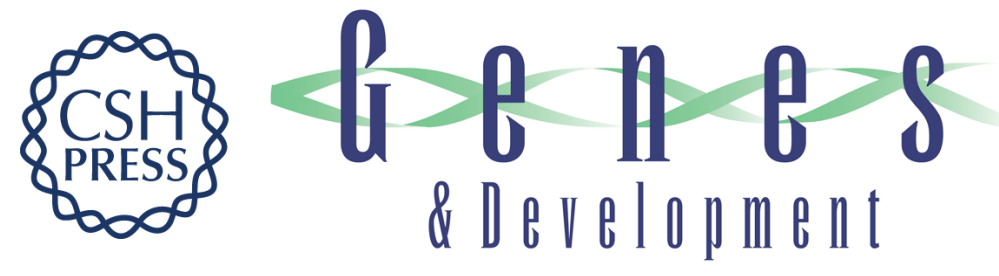

\section{Reciprocal interferences between nucleosomal organization and transcriptional activity of the yeast SNR6 gene.}

M C Marsolier, S Tanaka, M Livingstone-Zatchej, et al.

Genes Dev. 1995, 9:

Access the most recent version at doi:10.1101/gad.9.4.410

References This article cites 50 articles, 23 of which can be accessed free at: http://genesdev.cshlp.org/content/9/4/410.full.html\#ref-list-1

License

Email Alerting

Service

Receive free email alerts when new articles cite this article - sign up in the box at the top right corner of the article or click here.

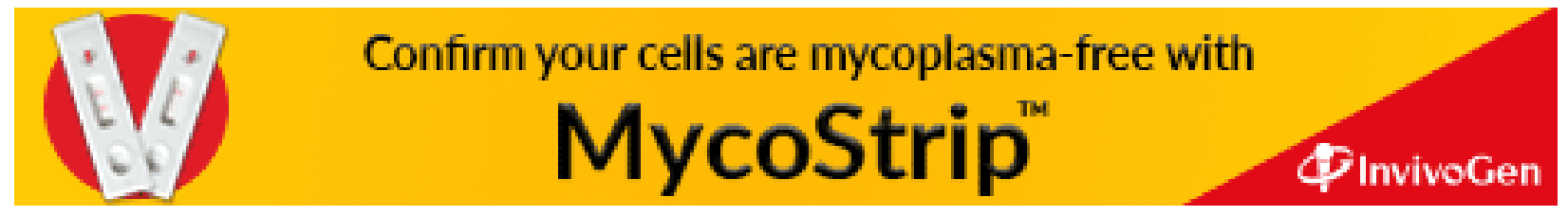

